\section{IP Periodica Polytechnica} Mechanical Engineering

\author{
57(2), pp. 53557 2013 \\ DOI: 10.3311/PPme.7046 \\ Creative Commons Attribution (1) \\ RESEARCH ARTICLE
}

\title{
Chemical etching of titanium samples
}

\author{
Lilla Nádai, Bálint Katona, Attila Terdik, Eszter Bognár
}

Received 2013-05-13, accepted 2013-09-04

\begin{abstract}
We studied chemical etching treatment on the surface of titanium implant materials, specifically $2 \mathrm{~mm}$ thick Grade 2 and nanoparticulate titanium discs, aiming to modify the surface roughness of samples. For chemical etching we investigated changes in reaction time on the surface (15-600 seconds). During the research we obtained the changes of thickness, mass and the surface roughness on both sides of every disc after the acid etching. The resulting surface was examined with optical stereo and reflected-light microscopy and electron microscopy.

As a result we found that the optimal etching parameters are an etching time of 30 seconds, etching solution of $9 \mathrm{~V} / \mathrm{V} \%$ hydrofluoric acid, $12 \mathrm{~V} / \mathrm{V} \%$ nitric acid and distilled water and a temperature of $30^{\circ} \mathrm{C}$, because with this protocol the burr from milling detaches from the surface.
\end{abstract}

\section{Keywords}

titanium $\cdot$ chemical etching $\cdot$ surface treatment $\cdot$ dental implant material · Grade2 titanium - nanoparticulate titanium

\section{Lilla Nádai}

Budapest University of Technology and Economics, Department of Materials Science and Engineering, H-1111 Budapest, Bertalan Lajos u. 7, Hungary e-mail: nadai.lilla@gmail.com

\section{Bálint Katona}

Budapest University of Technology and Economics, Department of Materials Science and Engineering, H-1111 Budapest, Bertalan Lajos u. 7, Hungary e-mail: beta-2@windowslive.com

\section{Attila Terdik}

Budapest Semmelweis University, Faculty of Dentistry, H-1085 Budapest,Üllői út 26, Hungary

e-mail: attilat@gmail.com

\section{Eszter Bognár}

Budapest University of Technology and Economics, Department of Materials Science and Engineering, H-1111 Budapest, Bertalan Lajos u. 7, Hungary

MTA-BME Research Group for Composite Science and Technology, H-1111 Budapest, Múegyetem rkp. 3, Hungary

e-mail: eszter@eik.bme.hu

\section{Introduction}

Dental implants are used to anchor prostheses into bone. Often these implants are made of a range of types of titanium. For titanium and its alloys to be integrated into living bone, it is important to study closely the surface and texture properties of the implant material.

Numerous researchers have proposed various titanium surface treatments to help bone anchor to its suitably roughened surface. Carlos Nelson Elias modified titanium dental implant surface morphology by acid etching and electrochemical treatments with the purpose of enhancing bone tissue response and decreasing the waiting time before an implant can be loaded. During the experiment an etching solution consisting of $\mathrm{HNO}_{3}$, $\mathrm{HCl}$ and $\mathrm{H}_{2} \mathrm{SO}_{4}$ was used. The acid etching treatment resulted in a homogeneous surface for the implants, where the average surface roughness parameter $(\mathrm{Ra})$ was $0.51-0.1$. Surface treatment of dental implants can change the chemical composition and morphology of the surface [1].

The manufacturer Struers recommends the most common chemical etchant for titanium, namely Kroll's reagent. This consists of $100 \mathrm{ml}$ water, 1-3 ml hydrofluoric acid and 2-6 ml nitric acid. The concentration can vary depending on the alloy and can be adjusted individually. The titanium can be colour etched with Weck's reagent composed of $100 \mathrm{ml}$ water and $5 \mathrm{~g}$ ammonium bifluoride. Another preparation of Struers is Electrolyte A3-1 which is advised for etching surfaces for materialographic preparations.

In our research we carried out chemical etching on implant materials, Grade 2 and nanoparticulate titanium in order to modify the surface roughness of the samples. The aim of our research was to find the optimal parameter settings, where the irregularities (burrs and grooves) caused by the milling procedure disappear. If these treatment settings can be made into a repeatable protocol then it could help create tailored implant surface textures to which living bone can reliably anchor. The protocol determined in our research can equally be applied to surface treatments where a smoother surface is required. 


\section{Materials and methods}

For our experiments we used Grade 2 titanium discs and nanoparticulate titanium discs (from now on we refer to this material simply as 'nano titanium'). Grade 2 is produced by the traction of raw titanium into a bar, whereas nano titanium is produced by a treatment named equal-channel angular pressing [2]. During the pressing a very high mechanical stress arises. Due to the resulting heat, nanoscale crystals emerge. This structure has greater strength and toughness than ordinary titanium bars. $2 \mathrm{~mm}$ thick discs of both materials were machined, then sliced with a diamond cutter into 4 pieces (Fig. 1) creating a total of 24 samples for study.

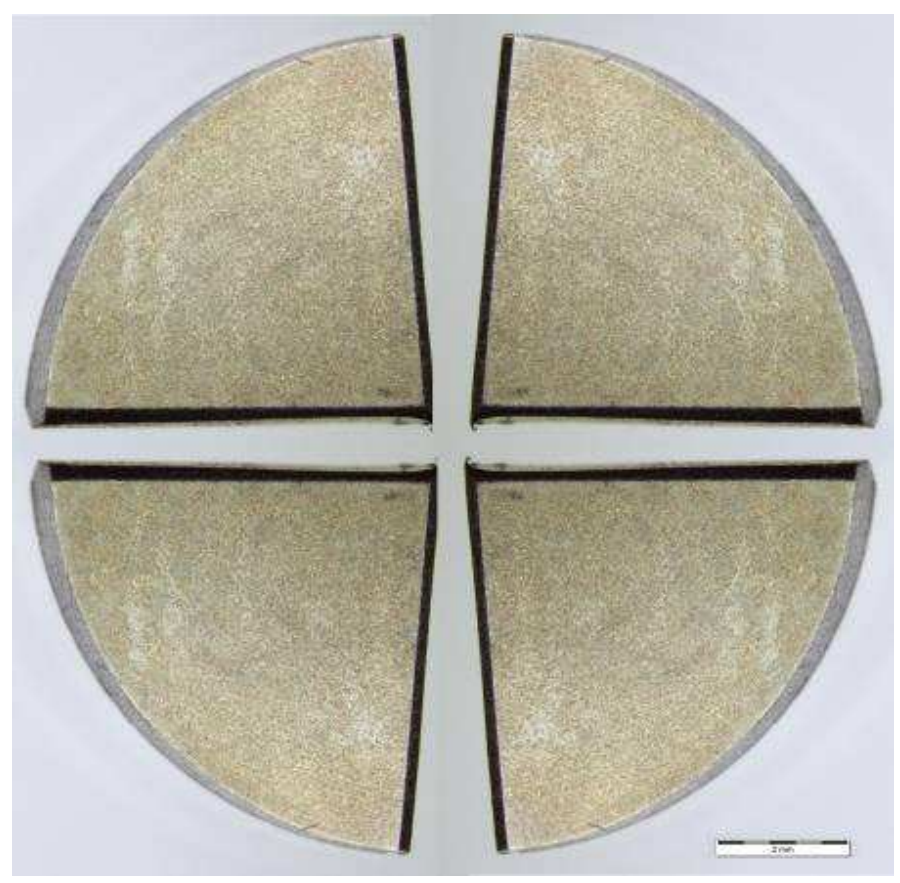

Fig. 1. Grade 2 disc cut into 4 pieces

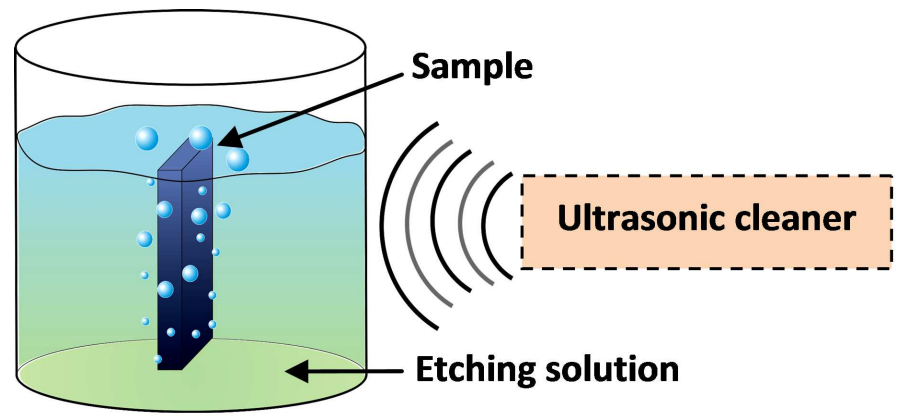

Fig. 2. The chemical etching process

Dental implants are formed by milling which causes burrs and leaves grooves in the surface.

\subsection{Method of Chemical etching}

In our research, milling-generated burrs were removed from the surface by chemical etching. We carried out the chemical etching of samples in an ultrasonic cleaner in order to increase the efficiency of the reaction. Fig. 2 shows a schematic illustration of the treatment.
During the process the reaction between the samples and the etching solution causes material to be lost from the treated samples. Chemical etching is affected by material composition, the etching solution, the temperature and the treatment period.

During the experiment we used an etching solution consisting of $9 \mathrm{~V} / \mathrm{V} \%$ hydrofluoric acid, $12 \mathrm{~V} / \mathrm{V} \%$ nitric acid and distilled water selected on Struers' recommendation and on the basis of preliminary experiments. Etching is an exothermic process, so the system heats up. Since the etching solution intensity depends closely on temperature, we had to keep it at an optimal value of $30^{\circ} \mathrm{C}$ based on measurements. Chilled acetone cooled the reaction environment to keep the temperature of the etching solution at $30 \pm 1{ }^{\circ} \mathrm{C}$.

As the time taken by chemical etching is an important parameter for surface quality, we analysed samples with various treatment times. For both materials (Grade 2 and nano titanium) we applied the times shown in Tab. 1 .

Tab. 1. Etching time of the samples

\begin{tabular}{cc}
\hline Sample No. & Etching time (secs) \\
\hline 1 & 15 \\
2 & 30 \\
3 & 60 \\
4 & 120 \\
5 & 180 \\
6 & 240 \\
7 & 300 \\
8 & 360 \\
9 & 420 \\
10 & 480 \\
11 & 540 \\
12 & 600 \\
\hline
\end{tabular}

Before the treatment we measured thickness, mass and the surface roughness on both sides of the discs. As a single measurement is not reproducible and cannot provide reliable results, we defined the mass and the thickness of every disc from the average of three measurements, and the surface roughness on both sides of every sample from the average results measured of five different surface area. For the size measurements we used a micro meter, for weighing an analytical balance and for the surface roughness a surface gauge.

We carried out these measurements also after chemical etching, obtaining data on the surface quality and loss of material plotted against etching times.

\subsection{Results of Chemical etching}

Figures 3 and 4 show mass measurements of samples. Decrease of mass is represented in percentage in function of etching time. Hundred percent indicates the mass of samples before the etching treatment and respectively the material loss after etching is showed in percents. From the etching treatment we expect that longer etching time cause greater material loss. This thesis cannot be confirmed simply on the basis of the results, 


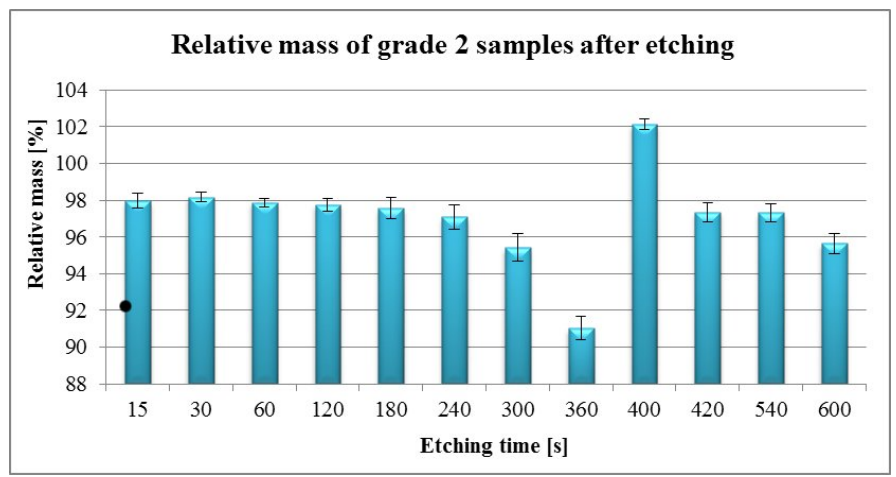

Fig. 3. Grade 2 titanium masses

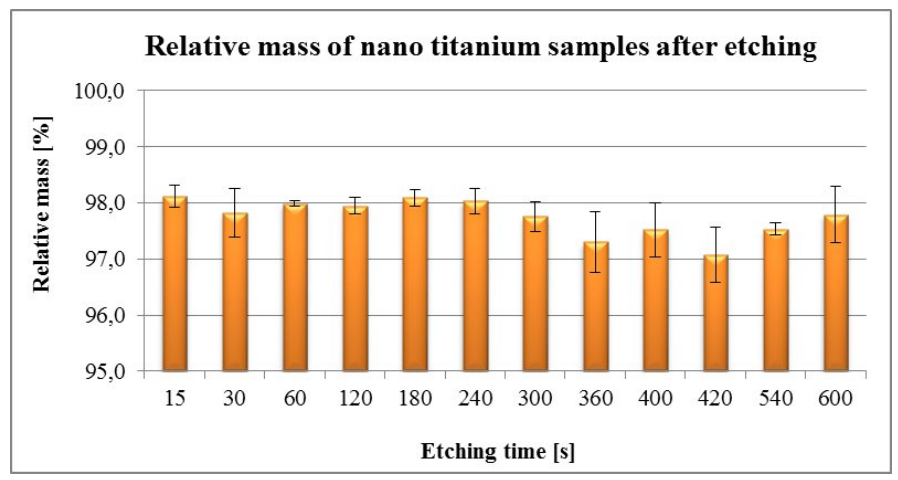

Fig. 4. Nano titanium masses

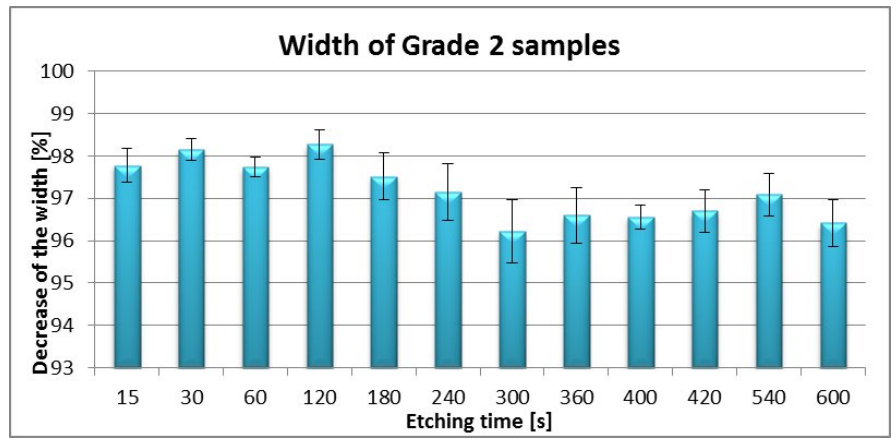

Fig. 5. Grade 2 titanium widths

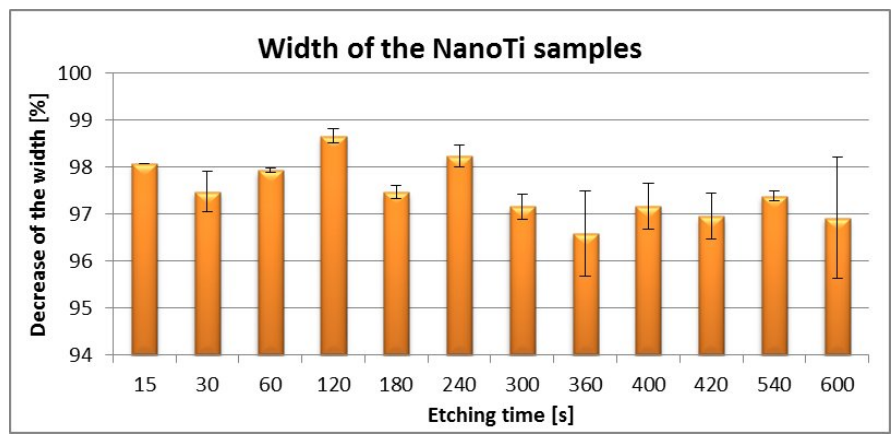

Fig. 6. Nano titanium widths

because on the surface of the samples there are different amount of burrs before the etching. Moreover during the treatment the mass of the precipitates can be different as well. Furthermore it can happen that the etching solution gets expended. Nevertheless we can observe on Fig. 3, that the mass of samples reduce continuously with the longer etching time till sample 8 (etching till 300 seconds). The outlying mass loss of sample number 8 might have been caused by the loss of extra burr. This can be

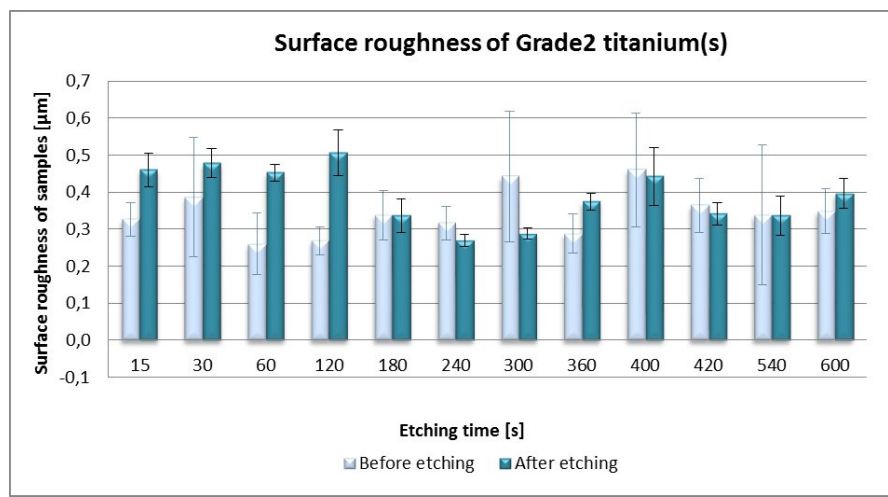

Fig. 7. Surface roughness of "s" side on Grade2 titanium samples

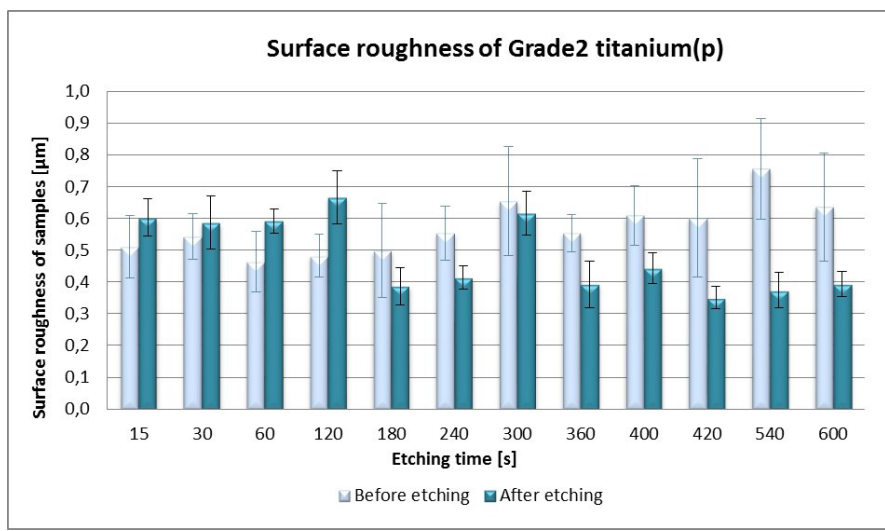

Fig. 8. Surface roughness of Grade 2 titanium "p" sides

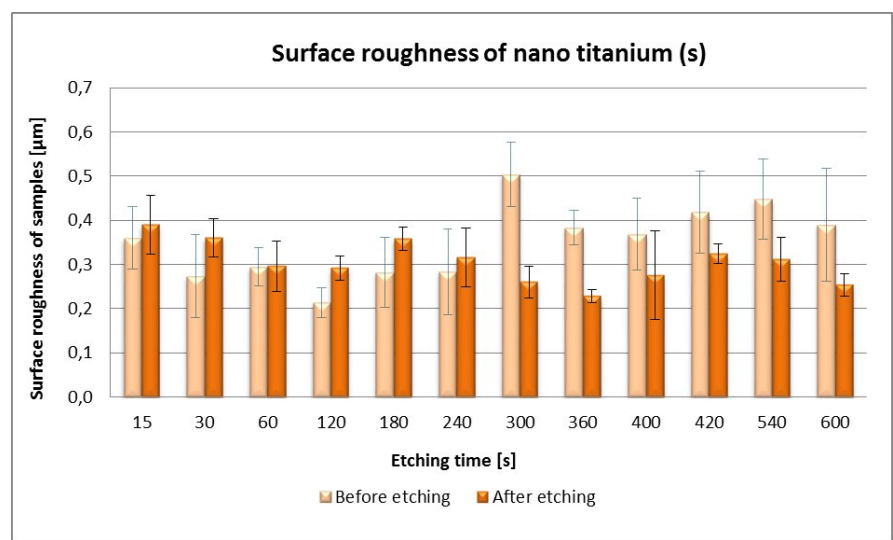

Fig. 9. Surface roughness of "s" side on nano titanium samples

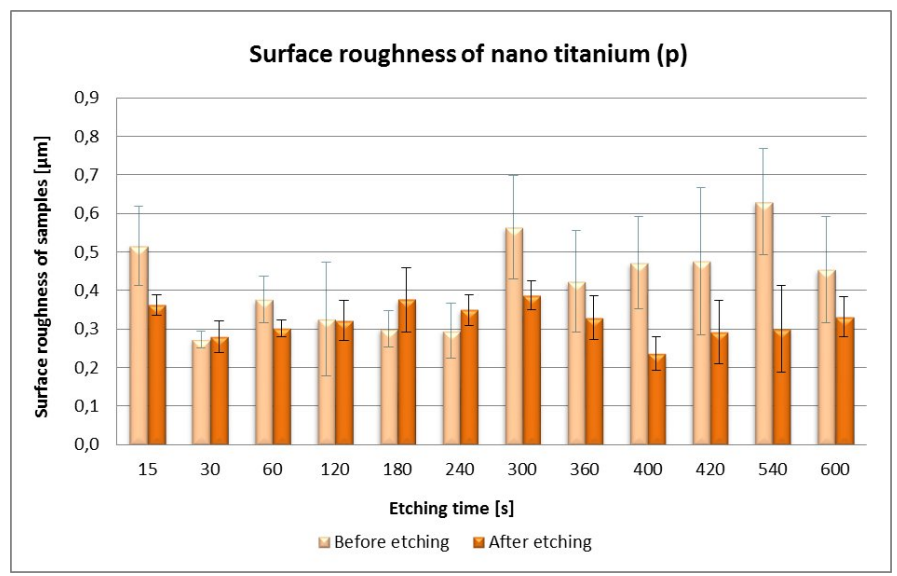

Fig. 10. Surface roughness of nano titanium "s" sides 
confirmed by Fig. 5 because the reduction of width at sample 8 is not outstanding which means the lot of material loss derived from the surface like burr. The breakout of sample 9 can be explained by the faulty mass measurement of this sample, because the mass can never increase during the etching treatment. If the sample 8 is not taken in to account the greatest material loss $(5 \%)$ at the Grade 2 samples are from sample 7 and 12.

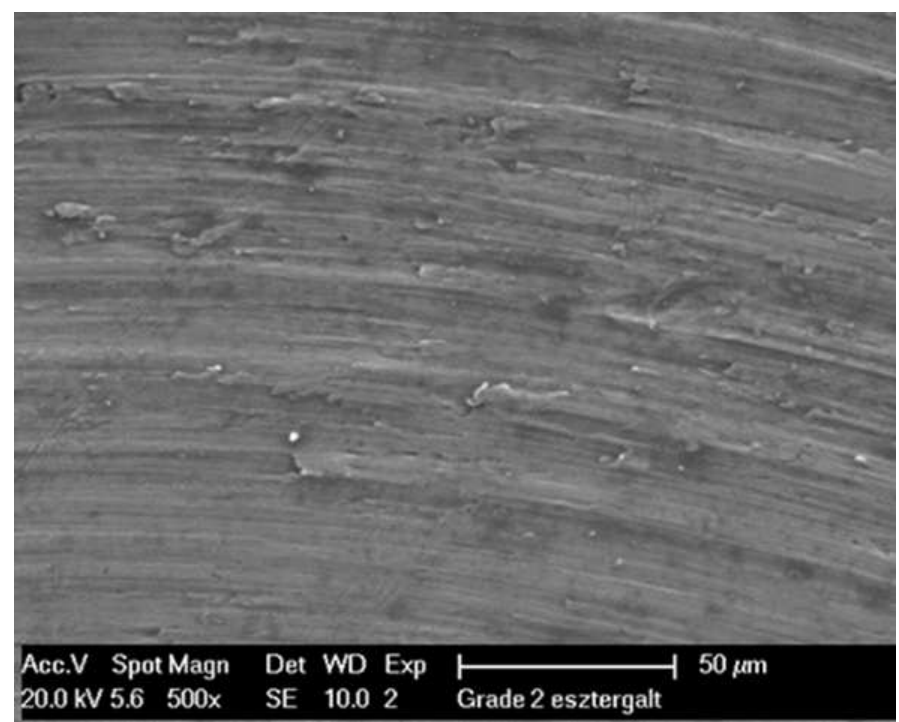

Fig. 11. Electron microscope image of Grade 2 sample ("p" side of the No.2) cut surface

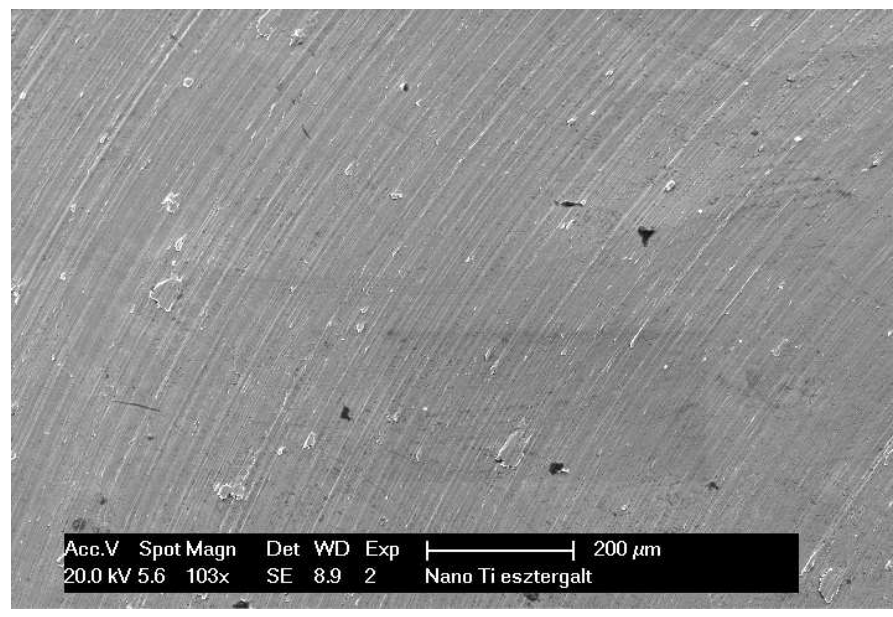

Fig. 12. Electron microscope image of the nano titanium sample surface (on "p side")

Mass distribution of the nano titanium before and after etching covers a smaller range than for the Grade 2 titanium samples. The least material loss at the nano titanium samples $(2 \%)$ happened at sample 1 etching 15 seconds $(0,0038 \mathrm{~g})$. Though the greatest material loss (3\%) occurred at sample etching 420 seconds $(0.0067 \mathrm{~g})$.

Fig. 5 and 6 show sample width before and after etching. The figures show with a good approximation that the longer etching time cause greater material loss but the difference between the greatest and the least width decrease is only $2 \%$ so it is not worth etching for a long time, accurately more than 300 seconds at both materials. The correlation coefficient between the de-

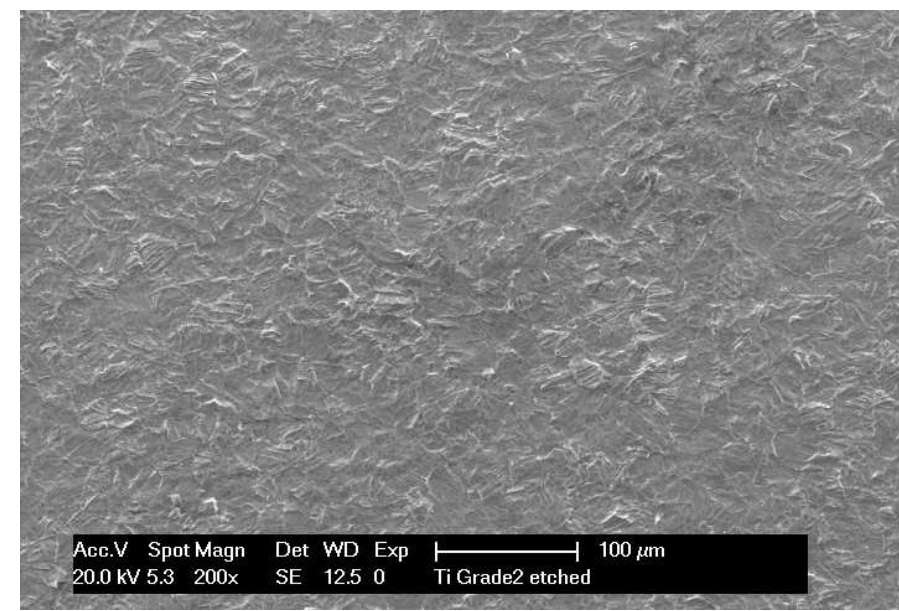

Fig. 13. Electron microscope image of the Grade 2 sample 2 (on "p" side) after 30 seconds etching

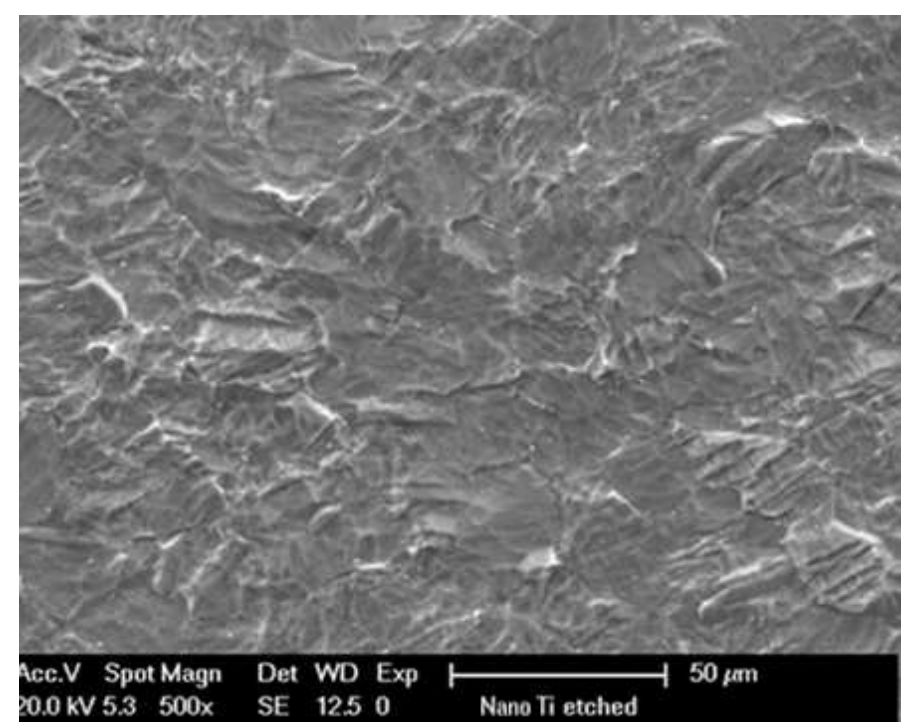

Fig. 14. Electron microscope image of the nano titanium sample 2 (on "p" side) after 30 seconds etching

crease of the mass and the width at the Grade 2 samples is 0,8 without the two outlier (samples 8 and 9) and at nano titanium samples 0,7 , which mean a strong relationship. Based on this data it is possible to determine the margin of the sample in order to reach the desired geometry after the etching treatment.

The two sides of the examined samples have slightly different surface roughness because of machining. The side with the higher surface roughness is labelled as "p-side" (pitted side), the side with the lower surface roughness is labelled "s-side" (smooth side). In order to unambiguously distinguish the two sides we marked the p-sides with a black dot. Small sample size in some cases might have hindered surface roughness measurement because of the displacement of the sample and the proper positioning of the measurement head.

The average surface roughness of "s" sides are shown in Fig. 7 and Fig. 8, and the average surface roughness of "p-sides" in Figs. 9 and 10 The surface roughness improvement is remarkable at the " $p$ " side of both materials which has rougher surface before the etching. Comparing the roughness on the sides of the 
Grade 2 samples, we determined after etching that at the first six samples the difference is in the interval $0,12-0,15 \mu \mathrm{m}$. In case of the 300 seconds etched samples, they get only $0-0,04 \mu \mathrm{m}$. The zero roughness difference between the sides was measured at sample 12. The greatest difference between the sides turns up at the sample etching 300 seconds at both materials. The smallest difference at the nano titanium samples is on the sample 11 (etching $540 \mathrm{sec}$.). Furthermore the roughness difference between the sides at nano titanium is in interval 0,01-0,08 $\mu \mathrm{m}$. The surface roughness distribution in the function of time at the nano titanium samples covers a smaller range $0,22-0,39 \mu \mathrm{m}$ than for the Grade 2 titanium samples 0,27-0,6 $\mu \mathrm{m}$.

Although longer chemical etching time does not give unambiguously better surface roughness, the treatment can eliminate at the gross level burrs.

We examined the samples with stereo and reflected-light microscopy and electron microscopy. The electron-microscope images show the grooves on a cut Grade 2 and nano titanium sample. On the chemical etched surfaces of the same disc the burrs and grooves formed by milling have disappeared.

For optimal chemical etching we set the following preferences in order of importance:

1 burrless surface roughness

2 low material decrease

3 best reproduction

4 shortest etching time

5 applicable for all 2 raw materials

\section{Summary}

During our research we found that the chemical etching of disc-shaped samples of Grade 2 has an average mass loss in the interval 2-5\% without the outliers and the nano titanium 2$3 \%$.Mass distribution of the nano titanium before and after etching covers a smaller range than for the Grade 2 titanium samples. Between the greatest and the least width decrease turns up only $2 \%$. This means, that it is not worth etching long time, accurately more than 300 seconds at both material. The correlation coefficient between the mass and the width after etching show a strong relationship at both materials. This connection is very important for later measurement and for the geometrical design of the implant.

We carried out surface roughness measurements on every sample on 5 different points on both sides. We observed that after milling, the surface of the nano titanium samples is smoother than the surface of the Grade 2 samples. Hence with the same etching a smoother surface can be achieved with the nano titanium samples. Since the raw materials are identical, this difference is likely to be related to the nanoparticles. The resulting surface roughness on Grade 2 samples was in the interval of 0.3 $0.6 \mu \mathrm{m}$ and on nano titanium discs $0.2-0.4 \mu \mathrm{m}$.
The greater loss of material can damage screw threads possibly preventing good anchorage to bone. However, it can be observed that if the chemical etching is too brief a burrless surface cannot arise. Bearing both these constraints in mind, it is worth keeping the etching time as low as is compatible with getting a burrless surface.

As conclusion we determined the optimal etching protocol on the basis of the results considering the low material decrease and shortest etching time. As the electron-microscope images show that the burrs and grooves formed by milling have already disappeared after 30 seconds etching samples at both materials, the surfaces get homogeneous.

It seems the optimal etching protocol is etching time of 30 seconds, etching solution of $9 \mathrm{~V} / \mathrm{V} \%$ hydrofluoric acid, $12 \mathrm{~V} / \mathrm{V} \%$ nitric acid and distilled water with temperature of $30^{\circ} \mathrm{C}$. With this treatment protocol the cut burr detaches from the surface. Moreover the grooves formed by the machine milling started to etch, making the surface smoother.

Improved understanding of the surface behaviour of a range of grades of titanium under a variety of milling and etching protocols allows more precisely controlled surface microtexture in aid of better osseointegration where metal implant meets living bone.

\section{Acknowledgement}

We thank Miklós Weszl for his kind assistance with technical issues and Dr. György Krállics for making nanoparticulate titanium raw materials available.

\section{References}

1 Elias CN, Titanium dental implants surfaces, Matéria (Rio de Janeiro), 15(2), (2010), 138-142, DOI 10.1590/S1517-70762010000200008

2 Gubicza J, Fogarassy Z, Krallics G, Lábár J, Törköly T, Microstructure and Mechanical Behavior of Ultrafine-Grained Titanium, Materials Science Forum, 589, (2008), 99-104, DOI 10.4028/www.scientific.net/MSF.589.99

3 Nádai L, Katona B, Bognár E, Titán kémiai maratása és elektropolírozása, Múszaki Tudományos Füzetek- XVIII, (2013), 265-268. Fiatal Múszakiak Tudományos Ülésszaka - FMTÜ EME, Kolozsvár.

4 Katona B, Nádai L, Bognár E, Titán minták anodizálása és bakteriológiai vizsgálata, Múszaki Tudományos Füzetek - XVIII. Fiatal Múszakiak Tudományos Ülésszaka - FMTÜ EME, Kolozsvár, ( 2013), 181-184.

5 Tanner A, Dental Implants Infections, Clinical Infectious Diseases, 25(2), (1997), 213-7, DOI 10.1086/516243

6 Tajima K, Hironaka M, Chen K, Electropolishing of CP Titanium and Its Alloys in an Alcoholic Solution-based Electrolyte, Dental Materials Journal, 27(2), (2008), 258-265, DOI 10.4012/dmj.27.258

7 Li L, Kong Y, Kim K, Improved biological performance of Ti implants due to surface modification by micro-arc oxidation, Biomaterials, 25(14), (2004), 2867-2875, DOI $10.1016 /$ j.biomaterials.2003.09.048

8 Mohn D, Zehnder M, Stark WJ, Imfeld T, Electrochemical Disinfection of Dental Implants - a Proof of Concept, PLoS ONE, 6(1), (2011), e16157, DOI $10.1371 /$ journal.pone.0016157 